\title{
Multidisciplinary treatment of advanced thymic neuroendocrine carcinoma (carcinoid): Report of a successful case and review of the literature
}

\author{
Pier Luigi Filosso, MD, ${ }^{a}$ Guglielmo Maria Actis Dato, MD, ${ }^{b}$ Enrico Ruffini, MD, ${ }^{a}$ Sergio Bretti, MD, ${ }^{c}$ Franca Ozzello, MD, ${ }^{d}$
} and Maurizio Mancuso, MD, ${ }^{a}$ Torino, Italy

T hymic carcinoid (TC) is a rare entity: since the first description by Rosai and Higa ${ }^{1}$ in 1972, approximately 150 cases have been reported in the literature. These tumors are frequently associated with endocrinopathies (Cushing syndrome or multiple endocrine neoplasia type 1; MEN-1) and carry a poor prognosis. ${ }^{2,3}$ TCs present an aggressive biological behavior with a tendency to invade adjacent structures (mediastinal fatty tissue, lung, pericardium, and great vessels) and with a tendency for local recurrences or distant hematogenous metastases.

Surgery, when feasible, represents the treatment of choice ${ }^{3-5}$ even if, in some cases, radical resection is not achieved. The role of neoadjuvant or adjuvant therapy has not yet been assessed. We describe the successful multidisciplinary management of a giant TC treated with neoadjuvant radiotherapy/chemotherapy, radical surgical resection, and preoperative, intraoperative, and postoperative therapy with a somatostatin analog. In addition, we provide a review of the recent literature about the management of these tumors.

\section{Clinical Summary}

A 39-year-old man underwent a bioptic left anterior mediastinotomy for a large mediastinal mass, discovered after he presented with cough and dyspnea. Histology revealed grade 2 neuroendocrine carcinoma (atypical carcinoid) of the thymus. Neoplastic tissue strongly expressed somatostatin receptors $\left(\mathrm{sst}_{2}\right)$, and chromogranin immunostaining was positive. Total body computed tomographic (CT) scan showed involvement of the anterior mediastinum, of the thoracic inlet, and of the left lung (Figure 1). No distant metastases were seen. Indium 111 diethylenetriamine pentaacetic acid pentetreotide scintigraphy (Octreoscan; Mallincrodt Medical BV, Zaltbommel, The Netherlands) confirmed an elective uptake only in correspondence of the tumor (Figure 2).

\footnotetext{
From the Department of Thoracic Surgery a and Department of Cardiac Surgery, ${ }^{\mathrm{b}}$ University of Torino Italy San Giovanni Battista Hospital, Torino, Italy, and the Service of Medical Oncology ${ }^{\mathrm{c}}$ and Service of Radiation Therapy, ${ }^{\mathrm{d}}$ Civil Hospital, Ivrea, Torino, Italy

Received for publication Aug 22, 2003; revisions requested Sept 30, 2003 accepted for publication Dec 4, 2003.

Address for reprints: Pier Luigi Filosso, MD, University of Torino Italy, Department of Thoracic Surgery, San Giovanni Battista Hospital, Via Genova, 3, 10126 Torino, Italy (E-mail: pierluigifilosso@tiscalinet.it)

J Thorac Cardiovasc Surg 2004;127:1215-9

$0022-5223 / \$ 30.00$

Copyright @ 2004 by The American Association for Thoracic Surgery

doi:10.1016/j.jtcvs.2003.09.058
}

Serum chromogranin A and neural specific enolase (NSE) levels were $143.3 \mathrm{ng} / \mathrm{mL}$ (reference range, 20-100 $\mathrm{ng} / \mathrm{mL}$ ) and 83 $\mathrm{ng} / \mathrm{mL}$ (reference value, $<12.5 \mathrm{ng} / \mathrm{mL}$ ), respectively. The patient's clinical status was good, and no associate diseases were evident.

Neoadjuvant chemotherapy/radiotherapy was started-4 courses of cisplatin $\left(100 \mathrm{mg} / \mathrm{m}^{2}\right.$ on day 1$)$ and etoposide $(100$ $\mathrm{mg} / \mathrm{m}^{2}$ on days $1-3$ and 5 ) repeated every 3 weeks-followed by irradiation (42 Gy in 2-Gy daily fractions) with a $10-\mathrm{MeV}$ linear accelerator. Because of the presence of $\mathrm{sst}_{2}$ in the biopsy specimen, Octreotide (Sandostatina Novartis Pharma, Milan, Italy) was administered at $1500 \mathrm{mg} / \mathrm{d}$ subcutaneously for 15 days, shifting to the long-acting form (20 mg every 28 days; Sandostatina LAR Novartis Pharma, Milan, Italy).

Radiologic and radionuclide restaging (CT scan, magnetic resonance imaging, and Octreoscan) showed a moderate reduction of the mediastinal lesion (Figure 3), without evidence of distant metastases. Blood chromogranin A and NSE levels were 109 and $20.7 \mathrm{ng} / \mathrm{mL}$, respectively. Surgery was thus planned.

To prevent the occurrence of refractory hypotension caused by the release of vasoactive peptides during surgical manipulation of the tumor, $100 \mathrm{mg}$ of Octreotide was administered subcutaneously before the operation and continuously at $50 \mathrm{mg} / \mathrm{h}$ intravenously during surgery. Femoral vessels were prepared in case cardiopulmonary bypass was needed.

A left lateral cervicotomy (medial to sternocleidomastoid muscle) and a median sternotomy were performed. The tumor was easily dissected free from the right hemithorax, but the involvement of the thoracic inlet necessitated the resection of the left brachiocephalic vein and some centimeters of the subclavian and internal jugular veins.

A large tract of the involved pericardium, from the superior vena cava to the left hilum, was resected, but no heart infiltration was observed (Figure 4). The left main pulmonary artery was involved by the tumor, and left pneumonectomy was necessary. A transverse left sternotomy prolonged in an anterior thoracotomy in the fourth intercostal space was performed, and en bloc resection of the mediastinum along with the left lung was performed (Figure 5). Sampling mediastinal lymphadenectomy was performed. A Prolene mesh (Ethicon, Inc, Somerville, NJ) was used to close the large pericardial defect.

The procedure and the postoperative course were uneventful. The patient was extubated 18 hours after the operation, transferred to the ward on postoperative day 3 , and discharged from the hospital in good clinical condition on postoperative day 14

Definitive histology showed a T2 N2 grade 2 neuroendocrine carcinoma (atypical carcinoid) of the thymus with mediastinal 


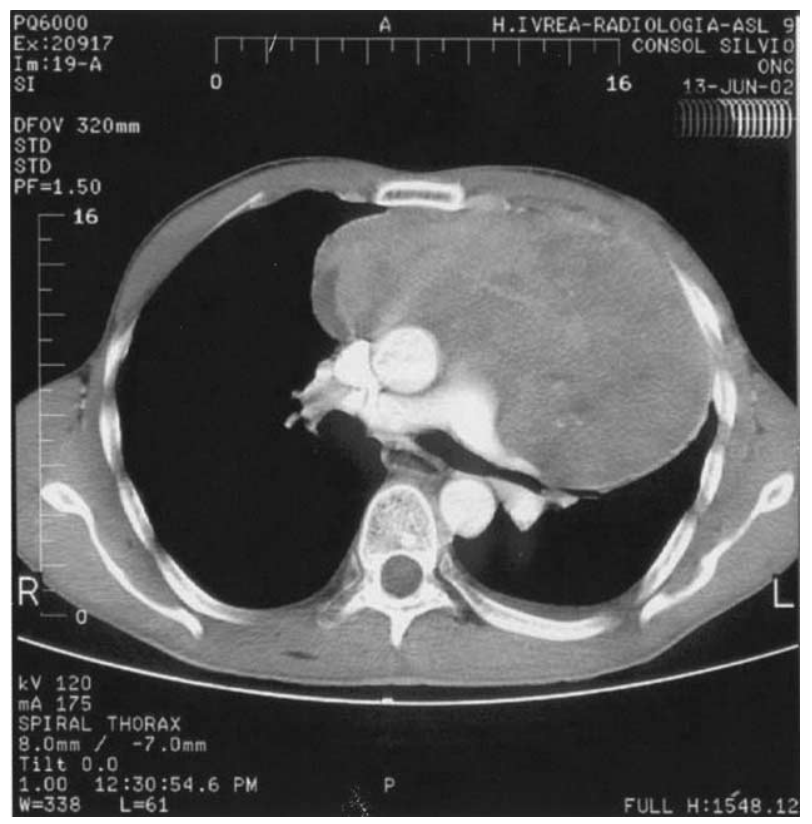

Figure 1. CT scan of a giant invasive thymic carcinoid.

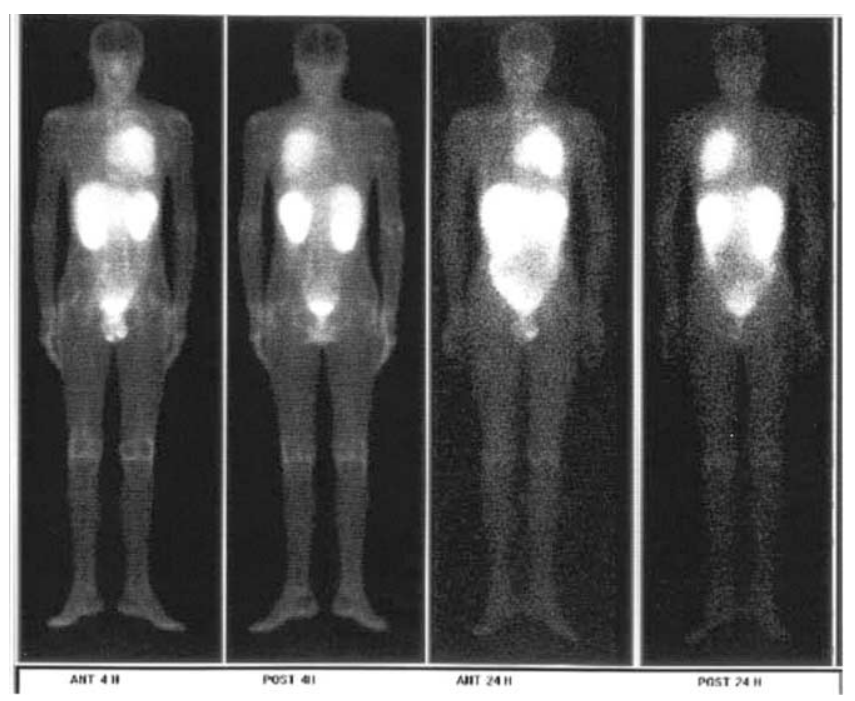

Figure 2. Octreoscan shows an elective uptake only in correspondence with the thoracic lesion: no other pathologic images are evident.

lymph nodal metastases and invasion of the lung. The surgical margins were tumor free.

Because of the radicality of the intervention, oncologists decided that adjuvant chemotherapy or radiotherapy was not indicated and put the patient under hormonal therapy with long-acting Octreotide $(20 \mathrm{mg})$. Follow-up was scheduled with blood marker tests (chromogranin A and NSE) every 3 months and total body CT scan and Octreoscan every 6 months.

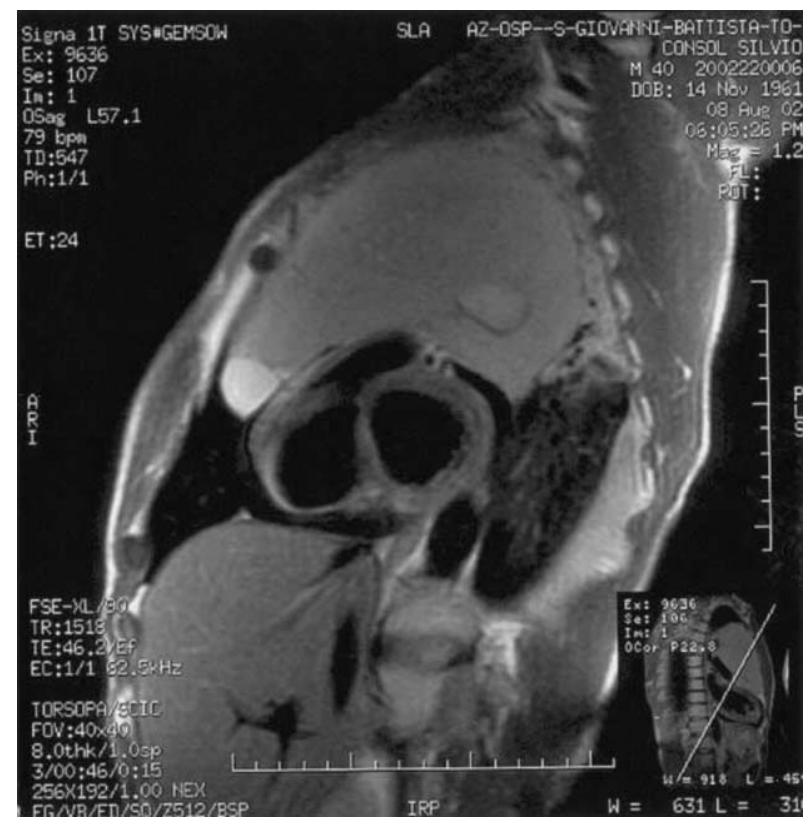

Figure 3. Preoperative thoracic magnetic resonance image (after the neoadjuvant treatment).

At the 18-month follow-up, the patient was in good clinical condition and had returned to his previous job (brick layer). Total body CT scan and Octreoscan showed an absence of local recurrence or distant metastases. Serum chromogranin A and NSE levels were $33 \mathrm{ng} / \mathrm{mL}$ (reference range, $20-100 \mathrm{ng} / \mathrm{mL}$ ) and 9.2 $\mathrm{ng} / \mathrm{mL}$ (reference value, $<12.5 \mathrm{ng} / \mathrm{mL}$ ), respectively. Medical therapy was well tolerated, and no important side effects were reported.

\section{Comment}

TC is a distinct clinicopathologic entity that has been confused with thymoma since Rosai and Higa ${ }^{1}$ first described this tumor as a separate entity in 1972 . TC represents only $4 \%$ of all anterior mediastinal tumors ${ }^{6}$ and is a rare entity: no more than 150 cases have been described in the literature.

TCs are 3 times more frequent in men than in women ${ }^{4,7}$; tumors have been described in patients from 8 years ${ }^{8}$ to 87 years old, ${ }^{9}$ but more frequently they occur between the fourth and the sixth decades of life. Most TCs present an aggressive biological behavior from the time of presentation. Symptoms are usually strictly related to the neoplastic mass effects: chest pain, cough, and dyspnea are frequently observed. Superior vena cava syndrome is described in approximately $20 \%$ of cases. ${ }^{3}$ A clinically apparent endocrinopathy develops in approximately half of patients: Cushing syndrome is the most frequent of these. de Perrot and associates ${ }^{10}$ reported that approximately 40 TCs associated with Cushing syndrome had been described in the literature since 1972 and that there was no difference in sex distribution in cases of TC and Cushing syndrome.

TC can occur in association with other endocrine neoplasms (eg, MEN-1), as Rosai and Higa ${ }^{11}$ first described in 1972. Since then, the association between TC and MEN-1 has been recognized 


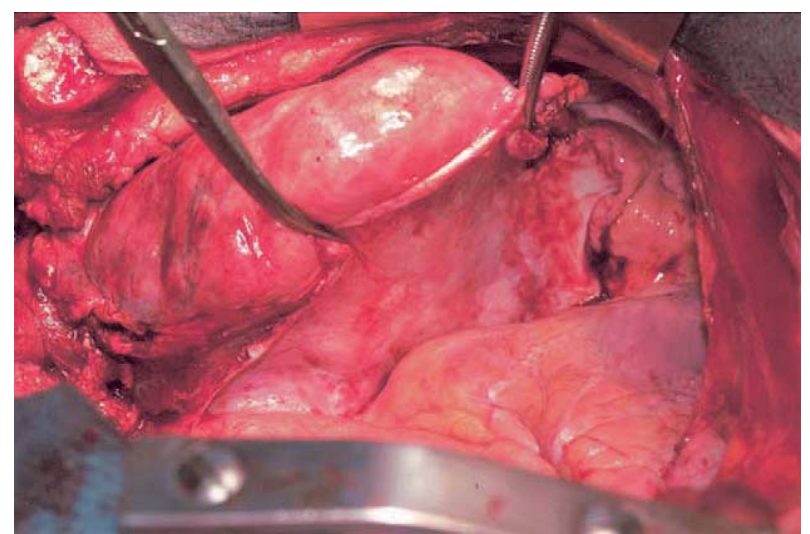

Figure 4. Operative view of the large thymic tumor: the pericardium is largely opened, but no heart infiltration is evident.

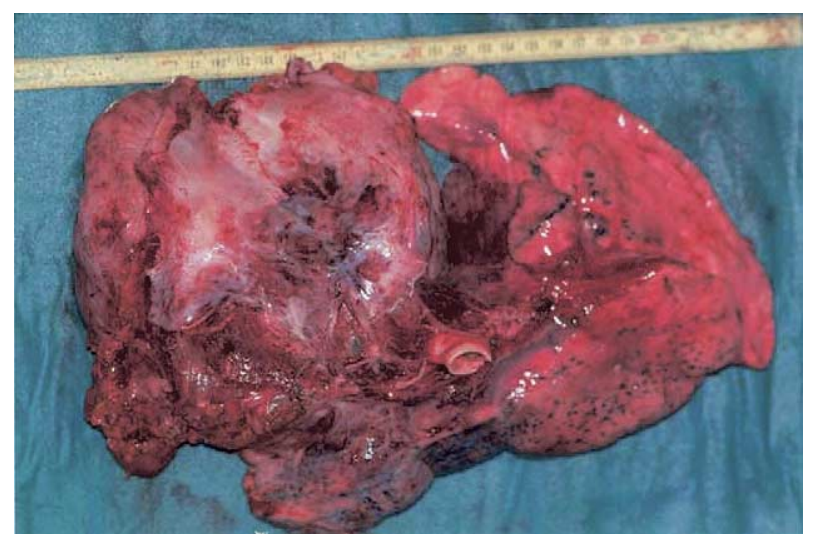

Figure 5. Surgical specimen of the radically resected thymic carcinoid.

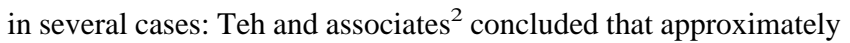
$20 \%$ of patients with TC presented with MEN-1. Patients with TC and MEN-1 are predominantly men and tend to be younger than those without any endocrine disease.

The aggressive biological behavior is in contrast with that of generally benign carcinoids that arise elsewhere in the body, in particular, bronchial carcinoid (BC). In our recently published series, ${ }^{12}$ we observed lymph node metastases in only $6(8 \%)$ of 75 typical BCs and in $14(36 \%)$ of 38 atypical ones. The 10- and 15-year survival was $93 \%$ and $84 \%$ for typical $\mathrm{BC}$ and $52 \%$ and $52 \%$ for atypical $\mathrm{BC}$, respectively.

TCs often present as locally invasive at the time of diagnosis $^{7,13}$; Wang and colleagues ${ }^{14}$ described locally invasive TC in 7 of 8 patients. In the series of Fukai and colleagues, ${ }^{4} 12$ of 15 TCs had invasive features.

Metastatic spread occurs by the hematogenous and lymphatic route, as with thymic carcinomas. Mediastinal lymph node metastases are frequently observed at presentation: de Montpréville and associates $^{3}$ and Fukai and colleagues ${ }^{4}$ reported metastatic TC in 7 of 14 and 9 of 15 patients, respectively.
TABLE 1. Histologic criteria for neuroendocrine tumors of the thymus classification ${ }^{17}$

\begin{tabular}{|c|c|c|c|}
\hline Variable & $\begin{array}{c}\text { Typical } \\
\text { carcinoid }\end{array}$ & $\begin{array}{l}\text { Atypical } \\
\text { carcinoid }\end{array}$ & $\begin{array}{l}\text { Small-cell } \\
\text { carcinoma }\end{array}$ \\
\hline $\begin{array}{l}\text { Mitoses per } 100 \\
\text { high-power } \\
\text { fields }\end{array}$ & $<10$ & $>10$ & Any \\
\hline Necrosis & Absent & Present & Present \\
\hline Pleomorphism & Minimal & Moderate & Moderate \\
\hline Nuclear molding & None & Minimal & Prominent \\
\hline Crush artifact & None & Minimal & Prominent \\
\hline
\end{tabular}

Distant metastasis sites include lung, bone, adrenal glands, liver, and spleen, in order of frequency. Distant metastases are observed in approximately $20 \%$ of patients with TC with a protracted clinical course. ${ }^{3}$

To simplify the nomenclature and make it more uniform, TCs have been reclassified according to specific criteria (mitotic activity, presence of necrosis, and cytologic atypia) as grade 1 neuroendocrine carcinoma (previous typical carcinoid), grade 2 neuroendocrine carcinoma (previous atypical carcinoid), and grade 3 neuroendocrine carcinoma (previously large-cell neuroendocrine carcinoma and small-cell carcinoma). ${ }^{15,16}$ Histologic criteria of this classification are shown in Table 1 . In Table 2, a proposed new TNM classification is shown. ${ }^{4}$

Most TCs are atypical carcinoids (or grade 2 neuroendocrine carcinoma) because of an increased mitotic count, nuclear pleomorphism, and the presence of necrosis. Immunohistochemical staining is usually strongly positive with chromogranin A and synaptophysin; this is a useful tool for a correct diagnosis of neuroendocrine carcinoma. Adrenocorticotrophic hormone staining is usually (but not necessarily) positive for TC associated with Cushing syndrome.

Incomplete resections are frequent. In this case, the local recurrence rate is high and survival is poor. Incomplete resections and local recurrences are the factors that influence the outcome in TC. ${ }^{3,17}$ de Montpréville and associates, ${ }^{3}$ on the basis of follow-up of 13 patients, observed that the median survival for complete resections $(n=4)$, incomplete resections $(n=5)$, and biopsy alone $(\mathrm{n}=4)$ was 71,30 , and 5 months, respectively.

Surgery, when feasible, is the treatment of choice. An aggressive approach often includes en-bloc resection of the tumor with the pericardium, lung, great vessels, or all of these. ${ }^{18}$ Median sternotomy is often indicated as a surgical approach, but occasionally, in case of large and invasive TC, the addition of an anterior (or posterolateral) thoracotomy should be considered to obtain better exposure of the involved hemithorax.

Sampling lymphadenectomy is mandatory for staging and oncologic planning. Economopoulos and colleagues ${ }^{7}$ and Fukai and associates ${ }^{4}$ concluded that long-term survival in TC can be achieved only by resection of both the primary tumor and the subsequent recurrences and metastases. Sakuragi and colleagues 5 reported a successful radical resection of a recurrent TC in which cardiopulmonary bypass was used to control the massive bleeding caused by dense adhesions between the sternum and the great vessels due to 3 previous interventions (2 sternotomies and 1 lateral thoracotomy). 


\begin{tabular}{|c|c|}
\hline$\overline{\mathrm{T} 1}$ & $\begin{array}{l}\text { Macroscopically completely encapsulated and } \\
\text { microscopically no evidence of capsular invasion }\end{array}$ \\
\hline $\mathrm{T} 2$ & $\begin{array}{l}\text { Macroscopic adhesion or invasion into surrounding fatty } \\
\text { tissue or mediastinal pleura; microscopic invasion into } \\
\text { the capsula }\end{array}$ \\
\hline T3 & $\begin{array}{l}\text { Invasion into neighboring organs (pericardium, lung, and } \\
\text { great vessels) }\end{array}$ \\
\hline T4 & Pleural or pericardial dissemination \\
\hline No & No lymph node metastasis \\
\hline N1 & Metastasis to anterior mediastinal lymph nodes \\
\hline N2 & Metastasis to intrathoracic lymph nodes \\
\hline N3 & Metastasis to extrathoracic lymph nodes \\
\hline Mo & No distant metastasis \\
\hline M1 & Distant metastasis (hematogenous) \\
\hline
\end{tabular}

The role of neoadjuvant/adjuvant therapy (chemotherapy or radiotherapy alone or in combination) has not been adequately assessed because of the low number of cases. Fukai and associates ${ }^{4}$ and de Perrot and colleagues ${ }^{10}$ reported the utility of postoperative radiotherapy to prevent local recurrences of invasive TC; 45 to 60 Gy were administered. Sakuragi and colleagues ${ }^{5}$ reported that 1 patient who underwent 4 interventions received 39 Gy of adjuvant radiotherapy after the third operation. Spaggiari and Pastorino ${ }^{18}$ reported use of adjuvant radiotherapy in a patient they operated on for an invasive atypical TC; this patient was free of disease 10 months after the intervention.

There are no standard regimens of chemotherapy, and only occasional experiences have been reported in the literature. Spaggiari and Pastorino ${ }^{18}$ reported that their patient received 3 cycles of neoadjuvant chemotherapy with ifosfamide and etoposide, but no signs of response were observed. Single agents or combination drug therapies with 5-fluorouracil, streptozocin, etoposide, or cisplatin have been proposed by Wang and colleagues ${ }^{14}$ and Takayama and colleagues ${ }^{19}$ : these had no significant effect on survival or recurrence rates. Gal and colleagues ${ }^{17}$ concluded that neither chemotherapy nor radiotherapy leads to differences in survival.

Our patient was a moderate responder to neoadjuvant chemotherapy/radiotherapy. This was enough to consider him for surgery and to start hormonal therapy with Octreotide. To our knowledge, this is the first case of successful multidisciplinary treatment of a TC with neoadjuvant chemoradiotherapy, radical resection, and hormonal therapy.

Neuroendocrine tumors, including thymic tumors, express $\mathrm{sst}_{2}$ at immunohistochemistry. In vivo $\mathrm{sst}_{2}$ expression is provided by indium 111 diethylenetriamine pentaacetic acid pentetreotide scintigraphy (Octreoscan). ${ }^{20,21}$

Recent generations of somatostatin analogs (Octreotide and lanreotide) bind with high affinity to $\mathrm{sst}_{2}$ receptors ${ }^{22,23}$; Octreotide has demonstrated good antiproliferative activity on neuroendocrine tumors, even if they are metastatic, without important side effects. ${ }^{24}$ Serum chromogranin A seems very useful for monitoring the disease, both with regard to recurrences and the efficacy of the Octreotide therapy. However, any suspicion of relapse has to be confirmed with CT scan and Octreoscan.
In conclusion, primary neuroendocrine thymic carcinomas are rare and aggressive tumors that are often characterized by local invasive behavior. An aggressive surgical approach remains the treatment of choice; preoperative chemotherapy/radiotherapy (cisplatin, etoposide, and 45 Gy of irradiation) and Octreotide therapy should improve the possibility of achieving a radical resection. Postoperative radiotherapy has been proposed to prevent local recurrences, with unpredictable results. Adjuvant therapy with Octreotide should be considered because of the well-recognized antiproliferative activity of this drug and its limited side effects. Because the in vivo $\mathrm{sst}_{2}$ expression is provided by Octreoscan, this procedure should be considered for follow-up along with CT scan.

\section{References}

1. Rosai J, Higa E. Mediastinal endocrine neoplasm, of probable thymic origin, related to carcinoid tumor. Cancer. 1972;29:1061-74.

2. Teh BT, Zedenius J, Kytola S, et al. Thymic carcinoids in multiple endocrine neoplasia type 1. Ann Surg. 1998;228:99-105.

3. de Montpréville VT, Macchiarini P, Dulmet E. Thymic neuroendocrine carcinoma (carcinoid): a clinicopathologic study of fourteen cases. J Thorac Cardiovasc Surg. 1996;111:134-41.

4. Fukai I, Masaoka A, Fujii Y, Yamakawa Y, Yokoyama T, Murase T, et al. Thymic neuroendocrine tumor (thymic carcinoid): a clinicopathologic study in 15 patients. Ann Thorac Surg. 1999;67:208-11.

5. Sakuragi T, Rikitake K, Nastuaki M, Itoh T. Complete resection of recurrent thymic carcinoid using cardiopulmonary bypass. Eur J Cardiothorac Surg. 2002;21:152-4.

6. Moran CA, Suster S. Spindle-cell neuroendocrine carcinoma of the thymus: a clinicopathologic and immunohistochemical study of seven cases. Mod Pathol. 1999;12:587-91.

7. Economopoulos GC, Lewis JW, Lee MW, Silverman NA. Carcinoid tumors of the thymus. Ann Thorac Surg. 1990;50:58-61.

8. Lin KL, Chen CY, Hsu HH. Ectopic ACTH syndrome due to thymic carcinoid tumor in a girl. J Pediatr Endocrinol Metab. 1999;12:573-5.

9. Rosado de Christenson ML, Abbott GF, Kirejczyk WM. Thoracic carcinoids: radiologic-pathologic correlation. Radiographics. 1999;19:707-11.

10. de Perrot M, Spiliopoulos A, Fisher S, Totsch M, Keshavjiee S. Neuroendocrine carcinoma (carcinoid) of the thymus associated with Cushing's syndrome. Ann Thorac Surg. 2002;73:675-81.

11. Rosai J, Higa E, Davie J. Mediastinal endocrine neoplasm in patients with multiple endocrine adenomatosis. A previously unrecognised association. Cancer. 1972;29:1075-82.

12. Filosso PL, Rena O, Donati G, Casadio C, Ruffini E, Papalia E, et al. Bronchial carcinoid tumors: surgical management and long-term outcome. J Thorac Cardiovasc Surg. 2002;123:303-9.

13. Valli M, Fabris GA, Dewar A, et al. Atypical carcinoid tumour of the thymus: a study of eight cases. Histopathology. 1994;24:371-5.

14. Wang DY, Chang DB, Kuo SH, et al. Carcinoid tumours of the thymus. Thorax. 1994;49:357-60.

15. Klemm KM, Moran CA, Suster S. Pigmented thymic carcinoids: a clinicopathological and immunohistological study of two cases. Mod Pathol. 1999;12:946-8.

16. Wick MR. Neuroendocrine neoplasia: current concepts. Am J Clin Pathol. 2000;113:331-5.

17. Gal AA, Kornstein MJ, Cohen C, Duarte IG, Miller JI, Mansour KA. Neuroendocrine tumors of the thymus: a clinicopathologic study. Ann Thorac Surg. 2001;72:1179-82.

18. Spaggiari L, Pastorino U. Double transmanubrial approach and sternotomy for resection of a giant thymic carcinoid tumor. Ann Thorac Surg. 2001;72:629-31.

19. Takayama T, Kameya T, Inagaki $K$, et al. MEN type 1 associated with mediastinal carcinoid producing parathyroid hormone, calcitonin and chorionic gonadotropin. Pathol Res Pract. 1993;189:1090-4.

20. Cadigan DG, Hollett PD, Collingwood PW, Ur E. Imaging of mediastinal thymic carcinoid tumor with radiolabelled somatostatin analogue. Clin Nucl Med. 1996;21:487-8. 
21. Lastoria S, Vergara E, Palmieri G, et al. In vivo detection of malignant thymic masses by indium-111-DTPA-D-pentetreotide scintigraphy. J Nucl Med. 1998;39:634-9.

22. Reisiene T, Bell GI. Molecular biology of somatostatin receptors. Endocr Rev. 1995;16:427-42.

23. Patel YC, Srikant CB. Subtype selectivity of peptide analogs for all five cloned human somatostatin receptors (hsstr 1-5). Endocrinolgy. 1994;135:2814-7.

24. Filosso PL, Ruffini E, Oliaro A, Papalia E, Donati G, Rena O. Long-term survival of atypical bronchial carcinoids with liver metastases, treated with octreotide. Eur J Cardiothorac Surg. 2002;21: 913-7.

\title{
Endometriosis-related pneumothorax: Clinicopathologic observations from a newly diagnosed case
}

\author{
Marco Alifano, MD, ${ }^{a}$ Alessandra Cancellieri, MD, ${ }^{\mathrm{b}}$ Adele Fornelli, MD, \\ Rocco Trisolini, MD, ${ }^{\mathrm{c}}$ and Maurizio Boaron, MD, ${ }^{\mathrm{a}}$ Bologna, Italy
}

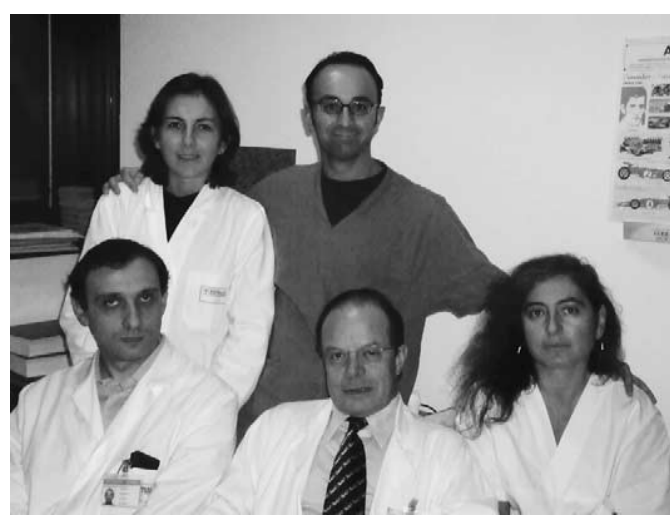

Bottom (left to right): Alifano, Boaron, Cancellieri. Top (left to right): Fornelli, Trisolini.
$\mathrm{P}$ neumothorax related to thoracic endometriosis has been generally considered to be a rare entity. ${ }^{1}$ Exact causative and pathogenic mechanisms are relatively poorly known, and controversies continue. ${ }^{2}$ Very recently, Alifano and coworkers $^{3}$ performed a prospective study on spontaneous pneumothorax (SP) in women of reproductive age and found that catamenial pneumothorax (CP), a typical manifestation of thoracic endometriosis, accounted for $25 \%$ of all cases of SP referred for surgical intervention. In that study all the patients with $\mathrm{CP}$ had diaphragmatic abnormalities (nodules or holes), and endometriosis was proved in all but one case. Treatment involved partial diaphragmatic resection, mechanical pleurodesis, and ovarian suppression therapy.

In the present article the clinicopathologic findings of a newly diagnosed case of endometriosis-related pneumothorax were studied to provide further insight into this condition.

From U.O. di Chirurgia Toracica, ${ }^{a}$ U.O. di Anatomia e Istologia Patologica, ${ }^{\mathrm{b}}$ and U.O. di Endoscopia Toracica, ${ }^{\mathrm{c}}$ Ospedale Bellaria-Maggiore, Bologna, Italy.

Received for publication Sept 27, 2003; accepted for publication Nov 3, 2003.

Address for reprints: Marco Alifano, MD, U.O. Chirurgia Toracica, Ospedale Maggiore, Largo Nigrisoli 2, 40133 Bologna, Italy (E-mail: marcoalifano@yahoo.com).

J Thorac Cardiovasc Surg 2004;127:1219-21

$0022-5223 / \$ 30.00$

Copyright $\odot 2004$ by The American Association for Thoracic Surgery

doi:10.1016/j.jtcvs.2003.11.044

\section{Clinical Summary}

A 39-year-old woman with an unremarkable clinical history was hospitalized for dyspnea and right-sided chest pain. Chest radiography revealed a complete right-sided pneumothorax. Tube thoracostomy was performed, obtaining immediate lung re-expansion. Drainage was discontinued on the third day, and the patient was discharged. Because pneumothorax had occurred on the third day of her menstrual cycle, $\mathrm{CP}$ was suspected, and therefore the patient was seen at the outpatient clinic on the fourth day of the subsequent cycle. The results of clinical examination and chest radiography were strictly normal. One week thereafter, mild exertional dyspnea appeared. Chest radiography and thoracic computed tomographic scanning revealed a partial pneumothorax. The decision to perform video-assisted thoracoscopy was made. At exploration, both the lung and the parietal pleura were normal, and no pulmonary air leak was identified at lung re-expansion with the cavity filled with saline solution. Exploration of the diaphragm showed multiple infracentimetric holes and brown-violet nodules, involving a $3 \times 5-\mathrm{cm}$ area of the tendinous portion of the muscle. On the basis of these findings and in agreement with previous experience, ${ }^{3}$ conversion to video-assisted minithoracotomy was made, and a partial diaphragmatic resection, including the pathologic area, was carried out. The defect was repaired with interrupted nonabsorbable sutures. Pleural brushing was performed.

The postoperative course was uneventful, and control inspiratory and expiratory chest radiographs were fully satisfactory. A 6-month ovarian suppression therapy (triptorelin, $3.75 \mathrm{mg}$ [Decapeptyl; Ipsen Biotech, Paris, France], administered intramuscularly once a month) was planned.

Grossly, the resected specimen was an extremely thin portion of diaphragm with several infracentimetric holes and nodules (Figure 1, $A$ ). In some areas the whole thickness of the diaphragm was less than $80 \mu \mathrm{m}$. At light microscopy, the diaphragm mainly 